\title{
FUNGSI BAHASA PADA WACANA BERASAN ETNIK REJANG DI KABUPATEN LEBONG
}

\author{
Mahmud Yunus $^{* 1}$, Dian Eka Chandra Wardhana ${ }^{2}$, Sarwit Sarwono ${ }^{3}$ \\ ${ }^{1,2,3}$ Program Studi Magister Pendidikan Bahasa Indonesia, Universitas Bengkulu \\ JIn. WR. Supratman, Kandang Limun, Kota Bengkulu, Indonesia \\ Email: mahmudy603@gmail.com ${ }^{* 1}$, dec.wardhana@unib.ac.id ${ }^{2}$, \\ sarwitsarwono@unib.ac.id ${ }^{3}$
}

\begin{abstract}
Abstrak
Tujuan penelitian ini untuk mendeskripsikan fungsi bahasa dalam prosesi Berasan pada etnik Rejang di Kabupaten Lebong. Metode penelitian menggunakan metode analisis isi kualitatif. Data utama penelitian berupa teks lisan Berasan. Teknik pengumpulan data menggunakan teknik dokumentasi, observasi, dan wawancara. Teknik analisis data dengan cara memaknai isi komunikasi, baik secara teks maupun konteks, membaca simbol-simbol, dan memaknai isi interaksi simbolis yang terjadi dalam komunikasi. Uji keabsahan data menggunakan triangulasi sumber data dan member check. Hasil penelitian menunjukkan bahwa adat Berasan etnik Rejang di Desa Bioa Sengok, Kecamatan Rimbo Pengadang, Kabupaten Lebong didomiansi fungsi referensial terdapat $67,74 \%$ sedangkan fungsi direktif dan fatik merupakan fungsi pelengkap masing-masing $25,80 \%$ dan $6,43 \%$. Fungsi yang sangat berpengaruh terhadap acara Berasan yaitu fungsi direktif sehingga terjalin kesepakatan kedua calon pengantin dalam melaksanakan pernikahan. Walaupun sebenarnya, acara Berasan ini merupakan acara formalitas adat karena kesepakatan sudah dibicarakan oleh kedua belah pihak terutama calon pengantin laki-laki dengan calon pengantin perempuan sebelum acara Berasan dilaksanakan.
\end{abstract}

Kata kunci: fungsi bahasa, Berasan, etnik Rejang

\section{ANALYSIS OF LANGUAGE FUNCTIONS IN BERASAN DISCOURSE ON THE REJANG ETHNIC GROUP IN LEBONG REGENCY}

\begin{abstract}
The purpose of this study was to describe the function of language in the procession of Berasan in the Rejang ethnic group in Lebong Regency. The research method uses qualitative content analysis methods. The main data of this research is in the form of oral text on Berasan. Data collection techniques using documentation, observation, and interviews. Data analysis techniques are by means of interpreting the content of communication, both in text and in context, reading symbols, and interpreting the content of symbolic interactions that occur in communication. Test the validity of the data using triangulation of data sources and member check. The results showed that the custom of Rejang ethnic Berasan in Bioa Sengok Village, Rimbo Pengadang District, Lebong Regency was dominated by $67.74 \%$ referential functions while directive and fatigue functions were complementary functions
\end{abstract}


respectively $25.80 \%$ and $6.43 \%$. The function that is very influential on the Berasan event is the directive function so that there is an agreement between the two prospective brides in carrying out the marriage. Although in fact, this Berasan event is a traditional formality event because the agreement has been discussed by both parties, especially the prospective groom and the bride before the Berasan event is held.

Keywords: function of language, Berasan, Rejang ethnicity

\section{A. Pendahuluan}

Adat perkawinan lahir, tumbuh, dan berkembang di masyarakat Indonesia, khususnya di dalam adat berasan etnik Rejang di Kabupaten Lebong. Masyarakat Indonesia adalah masyarakat yang Bhineka Tuggal lka, majemuk dan berbedabeda suku, ras, agama dan geografis. Kemudian, menjadi satu kesatuan Republik Indonesia sejak tanggal 17 Agustus 1945. Bahkan sudah bersatu sejak tanggal 28 Oktober 1928 yang diikat di dalam Sumpah Pemuda. Sebelum menjadi Provinsi Bengkulu, maka hiduplah adat dan budaya masing-masing di Kabupaten dan suku-suku yang ada di Provinsi Bengkulu khususnya, masyarakat di Kabupaten Lebong.

Adat merupakan gerak kehidupan manusia dalam kelompoknya, adat tumbuh, dan berkembang dalam masyarakat dan menjadi identitas pendukungnya (Setiadi dkk., 2006). Hukum adat merupakan hukum yang berlaku pada komunitas-komunitas adat tertentu di Indonesia. Kedudukannya menjadi penting bagi komunitasnya karena hingga saat ini masih secara efektif diterapkan oleh anggota-anggota komunitas (Suartina, 2020). Apa yang dibuat dan dipikirkan manusia melalui kegiatan adat melakukan kegiatan menciptakan melalui pikirannya termasuk kebudayaan, misalnya cara menghayati kematian, upacara kelahiran, perkawinan, sopan santun, tata cara makan pada waktu pesta, barang-barang yang dipakai untuk kehidupan. Begitu juga dengan prosesi pernikahan. Salah tahapan dalam adat suku Rejang adalah berasan, yang mana berasan merupakan prosesi terpenting menuju prosesi utama yaitu pernikahan. Karena berbicara adat, maka kita berbicara tentang bahasa. Dalam berasan di Kabupaten Lebong, masyarakat Lebong menggunakan bahasa Rejang.

Bahasa Rejang merupakan salah satu bahasa yang terdapat di Provinsi Bengkulu. Bahasa Rejang sangat berbeda dengan bahasa lain di Provinsi 
Bengkulu. Dalam sejarah disebutkan bahwa bahasa Rejang adalah bahasa suku Rejang, salah satu suku tertua di Sumatera. Wilayah yang menggunakan bahasa itu berada di Kabupaten Lebong, Kabupaten Rejang Lebong, Kabupaten Bengkulu Utara, Kabupaten Bengkulu Tengah, dan Kabupaten Kepahiang (Tim Pemetaan Bahasa, 2008). Salah satu pengguna bahasa Rejang terdapat di masyarakat Kabupaten Lebong. Bahasa Rejang merupakan bahasa yang dipergunakan sebagai alat komunikasi dan interaksi sehari-hari oleh masyarakat Rejang di Kabupaten Lebong, baik dalam slogan pemerintah, pergaulan di kalangan masyarakat, kegiatan musyawarah desa maupun juga dalam acara berasan (Astar, 2018).

Namun, dalam perkembangannya, masyarakat Rejang di Kabupaten Lebong terkhusus kalangan anak muda atau kaum milenial mulai kurang memahami bahasa atau istilah yang digunakan seperti dalam prosesi berasan yang merupakan tahapan sebelum dilaksanakannya pernikahan. Apalagi hari ini, prosesi berasan mulai tergerus dikarenakan peristiwa pernikahan campur. Misalnya: antara adat Rejang di Kabupaten Lebong dengan suku lain di luar Rejang. Maka bahasa yang digunakan dalam prosesi berasan tidak menggunakan bahasa Rejang melainkan bahasa Indonesia. Kemudian, faktor berikut yang menyebabkan kurangnya pemahaman masyarakat Lebong hari ini terhadap bahasa atau istilah yang digunakan didalam prosesi berasan yaitu karena bahasa dan tahapan prosesi berasan di Kabupaten Lebong dianggap rumit oleh masyarakat Lebong itu sendiri, dalam hal ini pihak keluarga yang menyelenggarakan suatu pernikahan campur.

Menurut Pareke \& Arisandi (2020) dalam adat masyarakat Rejang di Kabupaten Lebong terdapat empat tahapan sebelum pernikahan yaitu, (1) belinjang, (2) rasan muda (meletak uang), (3) rasan tua mbes caci (hantaran lamaran), dan (4) basen sasanak. Keempat tahapan tersebut bisa dikatakan tahapan wajib, dimana ada tahapan-tahapan yang jika dilakukan menjadi sesuatu hal yang baik, dan jika tahapan itu dilewati tidak mengurangi sakralnya tahapan utama. 
Empat tahapan ini menggunakan bahasa Rejang, seperti pada tahapan ketiga yakni rasan tua (lamaran/hantaran). Tahapan rasan tua ini melibatkan keluarga besar kedua belah pihak, ketua adat, dan segenap jajaran perangkat desa. Lazimnya prosesi rasan tua dilaksanakan di rumah si gadis. Sebelum proses mengantar uang ini pihak keluarga si bujang sudah melakukan persiapanpersiapan seperti mengundang kerabat dekat, tetangga, imam, perangkat desa, dan orang yang dituakan serta tokoh adat. Setelah semua berkumpul, terlebih dahulu akan diawali penjelasan ketua adat atau ketua kutai bahwa perundingan sebelumnya dengan pihak keluarga si gadis sudah rampung seperti uang hantaran, emas, dan berupa perlengkapan lainnya.

Tidak hanya itu, dalam proses hantaran, mes caci, lamaran ini, ada perlengkapan jamuan lainnya yang akan dibawa seperti: 1) potong ayam masak sawo keing (nasi ketan dicampur kelapa parut); 2) seperangkat sirih adat yang terdiri diri kapur, pinang; 3) bunga rampai (daun pandan, mawar melati yang dirangkai menjadi satu); dan 4) Juadeak (Kue wajik, benik, tat, koja).

Sementara di kediaman si gadis, pada malam mes caci (lamaran) juga mengundang para kepala desa, perangkat desa, imam, orang yang dituakan, kerabat dekat, dan tokoh adat untuk menghadiri penerimaan uang hantaran tersebut. Lazimnya, tempat acara di rumah si gadis. Saat proses penerimaan uang dari pihak si bujang terjadi didalam rumah. Sedangkan para tamu di luar rumah (di bawah tenda yang sudah disediakan beserta kursi).

Saat keluarga si bujang datang dan langsung disambut pihak si gadis dengan diwakili tuan rumah, akan menyampaikan ucapan selamat datang dan terima kasih atas kehadiran para tamu undangan serta menyampaikan maksud dan tujuan kedatangan dari pihak si bujang. Sebelum dilangsungkan acara penerimaan uang hantaran dari pihak si bujang, para tamu undangan terlebih dahulu dipersilahkan menyantap sajian. Setelah semua selesai, barulah acara mes caci (hantaran) dilaksanakan.

Diawali dengan sirih penyapa, sirih ini akan diletakkan di tengah kedua tokoh adat dari masing-masing pihak si bujang dan sigadis. Proses ini akan diawali oleh ketua adat dari pihak si gadis yang langsung berdialog dengan tokoh 
adat dari pihak si bujang. Dimana, dialog tersebut menyampaikan ucapan selamat datang ke kediaman pihak si gadis kepada keluarga si bujang. Dalam prosesi ini juga ada tahapan basen untuk penentuan tempat melangsungkan akad.

Istilah berasan dalam bahasa Rejang dapat diartikan sebagai musyawarah mengenai sesuatu hal yang dilakukan oleh kedua belah pihak untuk medapatkan kesepakatan. Dalam arti yang lebih khusus "berasan" sebagai pembicaraan kedua belah pihak untuk mendapatkan kesepakatan-kesepakatan yang berhubungan dengan proses menuju pernikahan (Dedi \& Cekman, 2018). Kegiatan dalam berasan untuk mencapai kesepakatan tersebut tidak terlepas dari penggunaan bahasa Rejang sebagai alat interaksi dan komunikasi kedua belah pihak (Siddik, 1980). Berasan adalah bagian dari kegiatan tutur yang merupakan dialog antara pemangku adat yang ditunjuk mewakili masing-masing calon mempelai. Kegiatan tutur menurut Keith Allan (dalam Rahardi, 2008) dan Syafryadin dkk., (2020) bertutur adalah kegiatan yang berdimensi sosial. Seperti lazimnya kegiatankegiatan sosial lainnya, kegiatan bertutur dapat berlangsung dengan baik apabila para peserta pertuturan itu semuanya terlibat aktif di dalam proses bertutur tersebut. Dalam Berasan, peserta tutur yang paling dominan melaksanakan kegiatan tutur adalah pemangku adat.

Berdasarkan uraian di atas, peneliti memiliki kekhawatiran apabila kegiatan Berasan ini tidak diteliti akan mengalami kepunahan karena acara Berasan ini sudah mulai jarang digunakan di masyarakat Rejang. Untuk itu, peneliti akan mendeskripsikan hasil penelitian tentang fungsi bahasa pada prosesi Berasan di Kabupaten Lebong dengan rumusan masalah "Bagimanakah fungsi bahasa pada wacana Berasan etnik Rejang di Kabupaten Lebong?" Hal ini bertujuan agar bisa mendeskripsikan fungsi bahasa yang terdapat pada wacana Berasan etnik Rejang di Kabupaten Lebong sebagai salah bahan pembelajaran bagi siswa tingkat SMP atau SMA salah satu jenis wacana seremonial yang perlu dilestarikan dan dikembangkan oleh siswa, misalnya dikembangkan menjadi sebuah cerpen atau puisi atau tulisan populer. Wacana sebagai bagian dari budaya di masyarakat penting dianalisis karena akan mampu memberikan contoh nilai-nilai kehidupan lewat bahasa yang disampaikan (Djajasudarma, 2010). 
Halliday (dalam Aziez \& Alwasilah, 1996) menjelaskan fungsi-fungsi bahasa meliputi: fungsi personal, fungsi direktif, fungsi referensial, fungsi fatik, fungsi metalingual, dan fungsi imajinatif. Kemudian, Chaer \& Agustina (2004) menjelaskan fungsi-fungsi bahasa dari beberapa sudut pandang yang dapat dilihat dari sudut penutur, pendengar, topik, kode, dan amanat pembicara. Dilihat dari segi penutur bahasa itu berfungsi personal, yaitu si penutur menyatakan sikap terhadap apa yang dituturkannya. Dilihat dari segi pendengar maka bahasa itu berfungsi direktif yaitu mengatur tingkah laku pendengar. Di sini bahasa tidak hanya membuat si pendengar melakukan sesuatu, tetapi melakukan kegiatan yang sesuai yang dilakukan si pembicara. Hal ini dapat dilakukan penutur dengan menggunakan kalimat-kalimat yang menyatakan perintah, himbauan, permintaan, maupun rayuan. Dilihat dari segi penutur dan pendengar bahasa berfungsi sebagai fatik yaitu fungsi menjalan hubungan, memelihara, memperlihatkan perasaan bersahabat dan solidaritas sosial. Dilihat dari segi topik ujaran maka bahasa itu berfungsi referensial disini bahasa itu berfungsi sebagai alat untuk membicarakan objek atau peristiwa yang ada di sekeliling penutur atau yang ada pada budaya umumnya (Noermanzah, 2019). Dilihat dari segi kode bahasa berfungsi metalingual atau metalinguistik yakni bahasa itu digunakan untuk membicarakan bahasa itu sendiri.

Fungsi bahasa dalam sebuah wacana membentuk teks yang mengandung nilai-nilai kehidupan yang bisa dijadikan contoh dalam memberikan pelajaran karakter kepada siswa. Dalam hal ini berasan mengandung makna-makna karakter komunikasi yang perlu diteladani oleh siswa, misalnya karakter diskusi, musyawarah, tanggung jawab, dan lainnya. Untuk itu, pentingnya diteliti fungsi bahasa pada wacana Berasan etnik Rejang di Kabupaten Lebong.

Penelitian wacana Berasan ini sudah dilakukan oleh Dedi \& Cekman, (2018) tentang kohesi leksikal dalam acara Berasan masyarakat Sindang Kelingi Musi Rawas. Berbeda pada penelitian ini yang mengkaji fungsi bahasanya dan acara Berasan di Kabupaten Rejang Lebong. Kemudian, penelitian yang lain oleh Yani (2016) yang fokus pada nilai agama, pengaruh Islam masuk di wilayah Rejang, dan unsur-unsur Islam mengenai aspek moral, sosial dan budaya pada 
adat upacara pernikahan suku Rejang.dalam upacara pernikahan adat Suku Rejang di Kecamatan Amen Kabupaten Lebong. Untuk itu, dapat ditunjukkan bahwa fungsi bahasa yang terdapat pada wacana Berasan etnik Rejang di Kabupaten Lebong belum ada yang meneliti. Dalam penelitian ini rumusan masalah yang akan dijawab yaitu Bagaimanakah fungsi bahasa yang terdapat pada wacana Berasan etnik Rejang di Kabupaten Lebong? Tujuannya untuk mendeskripsikan fungsi bahasa yang terdapat pada wacana Berasan etnik Rejang di Kabupaten Lebong.

\section{B. Metode Penelitian}

Metode penelitian yang yang digunakan yaitu metode analisis isi kualitatif. Metode analisis isi kualitatif ini mampu mengungkap makna teks dan konteks fungsi bahasa yang terdapat pada acara Berasan pada etnik Rejang di Kabupaten Lebong. Data utama penelitian berupa teks lisan acara Berasan yang diperoleh menggunakan gawai dengan cara merekamnya. Penelitian ini dilakukan di Desa Bioa Sengok, Kecamatan Rimbo Pengadang, Kabupaten Lebong, Provinsi Bengkulu. Pelaksanaan penelitian didasarkan pada jadwal yang sudah ditentukan sebelumnya. Jadwal tersebut menyesuaikan pada acara Berasan masyarakat Desa Bioa Sengok. Tahapan-tahapan pengumpulan data yang dilakukan secara sistematis sehingga dalam pelaksanaannya berjalan sangat efektif. Jadwal pengambilan data acara Berasan yaitu pada 26 September 2020.

Teknik pengumpulan data menggunakan teknik dokumentasi, observasi, dan wawancara. Teknik dokumentasi menggunakan alat berupa gawai untuk merekam proses acara Berasan dan medokumentasikan foto-foto acara Berasan. Observasi menggunakan instrumen lembar observasi yang berisi mengobservasi setiap kejadian yang terjadi di luar teks Berasan yang memiliki keterkaitan makna dengan teks Berasan. Sedangkan wawancara dilakukan dengan menggunakan pedoman wawancara yang dilakukan kepada pelaku adat Berasan. Pedoman wawancara dalam bentuk wawancara terbuka yang pertanyaannya berkaitan dengan makna-makna yang terkandung dalam setiap prosesi acara Berasan. 
Sebelum menganaliisis data peneliti melakukan transkripsi data teks Berasan dalam bentuk lisan menjadi teks tulisan yang selanjutnya dilakukan analisis data dengan menggunakan metode analisis isi. Teknik analisis data dengan cara memaknai isi komunikasi dengan bantuan tabulasi data, baik secara teks maupun konteks, membaca simbol-simbol, dan memaknai isi interaksi simbolis yang terjadi dalam komunikasi. Uji keabsahan data menggunakan triangulasi sumber data berupa data dokumentasi, observasi, dan wawancara. Selain itu, uji keabsahan data juga menggunakan teknik member check pada setiap kegiatan pengambilan dan penganalisisan data data.

\section{Hasil Penelitian dan Pembahasan}

\section{Hasil Penelitian}

Fungsi bahasa yang terdapat dalam acara Berasan etnik Rejang di Kabupaten Lebong dari hasil analisis data teks fungsi bahasa yaitu menggunakan fungsi direktif $25,80 \%$, fungsi referensial $67,74 \%$, dan fungsi fatik $6,43 \%$. Hal ini dapat ditunjukkan pada tabel berikut.

Tabel 1. Fungsi Bahasa yang Terdapat dalam Acara Berasan Etnik Rejang di Kabupaten Lebong

\begin{tabular}{clcc}
\hline No. & Fungsi Bahasa & Jumlah & Persentase \\
\hline 1 & Direktif & 8 & $25,80 \%$ \\
\hline 2 & Referensial & 21 & $67,74 \%$ \\
\hline 3 & Fatik & 2 & $6,44 \%$ \\
\hline & Jumlah & 31 & $100 \%$ \\
\hline
\end{tabular}

Dari hasil rekapitulasi hasil analisis fungsi bahasa yang dominan dalam penelitian ini adalah fungsi referensial. Hal ini dikarenakan setiap tuturan selalu muncul kata yang menunjukkan fungsi referensial. Dari hasil wawancara dan observasi lapangan, fungsi yang sangat berpengaruh terhadap acara Berasan yaitu fungsi direktif sehingga terjalin kesepakatan kedua calon pengantin dalam melaksanakan pernikahan. Walaupun sebenarnya, acara Berasan ini merupakan acara formalitas adat karena kesepakatan sudah dibicarakan oleh kedua belah 
pihak terutama calon pengantin laki-laki dengan calon pengantin perempuan sebelum acara Berasan dilaksanakan.

\section{Pembahasan}

Fungsi bahasa yang terdapat dalam acara Berasan masyarakat etnik Rejang di Kabupaten Lebong menggunakan fungsi direktif, fungsi referensial, dan fungsi fatik dalam menyepakati pelaksanaan pernikahan di Desa Bioa Sengok Kabupaten Lebong. Fungsi yang paling dominan yaitu fungsi bahasa referensial. Walaupun demikian, fungsi yang sangat berpengaruh terhadap acara Berasan yaitu fungsi direktif karena dengan fungsi ini, terjalin kesepakatan kedua calon pengantin dalam melaksanakan pernikahan. Acara Berasan ini merupakan acara formalitas adat karena kesepakatan sudah dibicarakan oleh kedua belah pihak terutama calon pengantin laki-laki dengan calon pengantin perempuan sebelum acara Berasan dilaksanakan.

Fungsi bahasa direktif yang digunakan bertujuan untuk menyepakati pelaksanaan pernikahan terdapat pada baris ke $5,6,7,8,9,10$ pada penutur 1 dan 2. Hal ini sesuai dengan pendapat Prayitno (2010) bahwa direktif permintaan adalah suatu tuturan yan bertujuan untuk memohon dan mengharapkan kepada mitra tutur supaya diberi sesuatu untuk menjadi sebuah kenyataan sebagaimana yang diminta oleh penutur. Sama halnya dijelaskan oleh Ibrahim (1993) dan Safira (2020), bahwa tindak tutur direktif memesan atau meminta (ordering) memiliki fungsi meminta, mengemis, memohon, menekan, mengundang, mendoa, mengajak, dan mendorong.

Fungsi bahasa direktif dalam dialog kedua adat pada acara berasan etnik Rejang di Desa Bioa Sengok, Kecamatan Rimbo Pengadang, Provinsi Bengkulu seperti dalam Ali Munandar tuturan 5 Muk iben capua upua mileak, coa te sako nikeak ade ba mahar. Magea kumu sudo, kedatangan keme yo lok masen anok udi. Do o baa de mahar caci rajo 25 juta. Nikeak umeak keme sesuai pertemuan pertamo te bel o bulen naep 31-1. Do o ban am keme min.

Maksudnya, dalam kutipan Nikeak umeak keme adalah pihak dari si bujang mengajukan permintaan kepada pihak si perempuan untuk pelaksanaan akad 
nikah agar dilaksanakan di kediaman si bujang. Mengingat permintaan tersebut merupakan keinginan dari orangtua si bujang. Selanjutnya, dalam contoh dua: "Keme kulo minoi tulung amen demingau sebelum akad coa si pas asai ne, awei ipe amen telau bilai ayok acara keme majok semulen udi mlanai moi dasei keme". Kata "minoi" adalah sebuah ungkapan permintaan yang dituturkan oleh penutur agar maksud permintaan mereka dikabulkan, penggunaan kata "minoi tulung" yang berarti "minta tolong" termasuk kata yang sopan, dibandingkan hanya menggunakan kata "minoi" saja. Selanjutnya, fungsi direktif terdapat pada kutipan "Coa nam umeak keme bae, keme biak arok ne amen akad dilangsungkan umeak keme" sebuah ungkapan permintaan persetujuan agar akad dilaksanakan di kediamannya.

Fungsi referensial yang digunakan dalam adat berasan etnik Rejang di Desa Bioa Sengok Kabupaten Lebong bertujuan untuk membicarakan objek atau peristiwa yang ada di sekeliling penutur. Seperti kata, keme, kumu, kumu-kumu, kwaai dan udi. Hal ini sesuai dengan pendapat Chaer \& Agustina (2004) bahwa fungsi referensial ini yang melahirkan paham tradisional bahwa bahasa itu adalah alat untuk menyatakan pikiran, untuk menyatakan bagaimana si penutur tentang dunia di sekelilingnya. Berikut indikator referensial: a) membicarakan objek atau peristiwa (membuat berita), b) pemahaman terhadap dunia sekitar (menyampaikan informasi, dan membuat pernyataan).

Dalam teks ini, referensial memiliki ciri khas menggunakan bahasa yang lebih sopan sesuai situasi dan kondisi yang sedang terjadi, namun maknanya tetap sama. Contohnya kata ganti keme oleh perwakilan keluarga untuk menggantikan kata $u k u$ yang bearti saya dalam menyampaikan niatan, hajatan dari pihak keluarga kepada keluarga besan bertujuan untuk menunjukkan rasa sopan santun penutur kepada khalayak banyak, sekaligus kata keme itu merupakan kata ganti yang mewakili orang banyak dari pihak mereka yang hadir di prosesi berasan tersebut. Berikut beberapa kutipan keme di teks adat berasan masyarakat Rejang di Kabupaten Lebong yang dituturkan Ali Munandar "maksud"Keme moi minyo ade ba untuk maneu asen de sudo ne. Ade a penemin keme berupa caci, emas, liket sengok berupo kain untuk anok udi. 
Sama halnya dalam penggunaan kata "kumu-kumu" yang berarti "anda sekalian" yang juga menggantikan kata "kumu" yang berarti "kamu" terlihat pada kutipan "Mokasiak ngen kumu-kumu amen memang temimo permintaan keme untuk akad neak dasei keme. Ade kulo kelok pihak smanei untuk majok belek smulen keme sebelum akad baso ne melandai. Keme minoi waktau ne demingau sebelum akad, awei ipe kekiro". Penggunaan kata "keme", "kumu-kumu" hampir terdapat di setiap kutipan kalimat yang dituturkan oleh penutur, untuk itu fungsi referensial adalah fungsi yang dominan dalam wacana teks berasan masyarakat Rejang ini. Berikut contoh lain kata ganti kumu-kumu yang digunakan dalam adat berasan etnik Rejang di Desa Bioa Sengok, Kabupaten Lebong.

P.2-T-2 : Dio ba ade kumu rombongan de pei sapei, alhamdulillah amen asen de sudo ne nam te melanjutkan. Sebagai keme pihak smulen temimo penemin kumu-kumu yo berupa caci, emas, liket sengok berupo kain dan ade kulo rubo anok semulen keme dan kenliak keme yo penemin kumu-kumu yo sesuai gen janyai te waktau pertamo o.

Ini ada kamu rombongan yang baru sampai, alhamdulillah kalau Berasan yang sudah kita laksanakan, maka bisa kita lanjutkan. Sebagai kami pihak si gadis menerima bawaan kalian yakni berupa uang, emas, kain dan ada juga oleh-oleh untuk anak gadis kami dan kami lihat bawaan kalian sudah sesuai dengan janji waktu pertemuan pertama dulu). Jumlah kata ganti kumukumu yang ditemukan dalam percakapan di atas sebanyak 4 kali.

P.2-T.8 : Amen telau bilai ayok acara o calon ngenyan coa buliak kelua ayok akad ne, ijai demingau ayok ne o ba permintaan keme ngen kumu-kumu yo.

(Kalau tiga hari sebelum acara nanti calon mempelai wanita tidak boleh keluar sebelum akadnya, jadi seminggu sebelumnya itulah permintaan kami kepada kalian ini)

P.2-T.13 : Terimo kasiak ngen kumu-kumu yo. (bersalaman)

(Terima kasih kepada kalian ini. (bersalaman).

Fungsi fatik atau petata-petiti dalam teks Berasan ini tidak terlalu dominan, fungsi fatik terdapat di awal wacana dan di akhir wacana ini karena fungsi fatik sendiri sebagai fungsi menjalin hubungan, memelihara, dan memperlihatkan perasaan bersahabat atau solidaritas sosial. Sama halnya diungkapkan Sudaryanto (1990), bahwa fungsi fatis atau fatik merupakan bahasa sebagai pembuka, pembentuk, pemelihara hubungan atau kontak pembicaraan penyimak. 
Fungsi ini disejajarkan dengan faktor kontak yang terjadi dalam awal komunikasi.

Dalam teks percakapan ini fungsi bahasa fatik terdapat dalam Penutur I (Ali Munandar) bait 1 dan 3:

P.1-T.1 : Asai tekecep tebau nak talang. Asai tekenem bioa nak imbo. Asai mendaki pungguk mendatea.

(Rasa tecicip tebu di talang. Rasa teminum air di Rimba. Rasa mendaki tumpukan datar).

P.2-T.1 : Dio ade iben sapei daet, moi mbuk iben. Iben ade delamea, gambea ade

decaik, pinang ade desisit, rokok ade depun. Ibenne iben pena'ak magea de suko nangea. Salang tun dumai belek moi talang, salang tun talang belek moi sadei. Dapet keno ta'ok ngen tawea.

(Ini ada sirih sampai darat, pergi makan sirih. Sirih ada selembar, gambir ada satu, pinang ada sesisit, rokok ada satu. Sirihnya sirih teguran untuk yang suka dipanggil. Orang di ladang pulang ke talang, orang talang pulang ke dusun. Dapat terkena teguran dengan daun setawar).

P.1-T.3 : Do o ba, lubuk musin penan ne kan, amen berembuk bik sudo Keme lok smapei maksud dan tujuan.

(Itulah, lubuk musin tempatnya ikan, kalau berembuk sudah selesai kami mau menyampaikan maksud dan tujuan.)

P.2-T.3 : Sebelum ite muloi, dio ade ba bioa nyoa ngen sawo sebagai tando basen.

(Sebelum kita mulai, ini ada air kelapa dan ketan sebagi tanda kita berasan).

Ungkapan-ungkapan yang digunakan biasanya sudah berpola tetap, seperti pada waktu pamit, berjumpa atau menanyakan keadaan. Fungsi ini terlihat di kutipan "Dio ade iben sapei daet, moi mbuk iben. Iben adedelamea, gambea ade decaik, pinang ade desisit, rokok ade depun. Ibenne iben pena'ak magea de suko nangea. Salang tun dumai belek moi talang, salang tun talang belek moi sadei. Dapet keno ta'ok ngen tawea." Maksud dari kalimat tersebut adalah pihak tuan rumah menerima kedatangan pihak tamu. Kemudian, fungsi fatik lainya terdapat di akhir wacana "Terimo kasiak kulo ngen kumu-kumu yo" ucapan terima kasih yan menandakan bahwa hubungan kedua belah piha terlihat hangat dan saling menghargai. 


\section{Simpulan dan Saran}

Berdasarkan hasil penelitian ini dapat disimpulkan bahwa fungsi bahasa yang muncul dalam penelitian ini adalah fungsi referensial, fungsi direktif, dan fungsi fatik. Fungsi-fungsi bahasa ini saling membangun acara Berasan dalam menyepakati prosesi acara pernikahan. Fungsi yang paling dominan muncul yaitu fungsi referensial. Walaupun demikian, fungsi yang sangat berpengaruh terhadap acara Berasan yaitu fungsi direktif karena dengan fungsi ini, terjalin kesepakatan kedua calon pengantin dalam melaksanakan pernikahan. Acara Berasan ini merupakan acara formalitas adat karena kesepakatan sudah dibicarakan oleh kedua belah pihak terutama calon pengantin laki-laki dengan calon pengantin perempuan sebelum acara Berasan dilaksanakan.

Selain itu, dengan hadirnya fungsi referensial, fungsi direktif, dan fungsi fatik pada acara adat Berasan etnik Rejang di Kabupaten Lebong, maka tahapantahapan dalam prosesi tersebut secara otomatis tahapan-tahapan tersebut menjadi sempurna. Seperti salam pembuka yang disampaikan dengan bahasa yang apik, petata-petiti yang menciptakan suasana antusias dari masyarakat untuk mengetahui makna dari petata-petiti tersebut, dan dialog-dialog yang membangun suasana kekeluargaan.

Hasil penelitian ini baru sebatas analisis isi fungsi bahasa pada acara Berasan etnik Rejang di Kabupaten Lebong yang difokuskan di Desa Bioa Sengok, Kecamatan Rimbo Pengadang, Kabupaten Lebong, Provinsi Bengkulu. Untuk itu, hasil penelitiannya masih belum lengkap mengungkap makna secara kontekstual acara Berasan dan belum mewakili seluruh acara Berasan di Kabupaten Rejang Lebong. Harapannya penelitian ini bisa dilanjutkan dengan metode kualitatif naturalistik yang dilakukan di Kabupaten Rejang Lebong secara keseluruhan. Kemudian, acara Berasan ini hanya difokuskan pada acara Berasan untuk acara lamaran pernikahan. Peneliti berikutnya bisa meneliti acara Berasan pada acara-acara lainnya. 


\section{Daftar Pustaka}

Astar, H. (2018). Realisasi Konsep Bahasa Indonesia dalam Bahasa Rejang. Sirok Bastra, 5(2). 113-114. doi:10.37671/sb.v5i2.101

Aziez, F. \& Alwasilah, A. C. (1996). Pengajaran Bahasa Komunikatif. Bandung: PT Remaja Rosdakarya.

Chaer, A. \& Agustina, L. (2004). Sosiolinguistik Perkenalan Awal. Jakarta: PT Rineka Cipta.

Dedi, D., \& Cekman, C. (2018). Kohesi Leksikal dalam Acara Berasan Masyarakat Sindang Kelingi Musi Rawas. Silampari Bisa: Jurnal Penelitian Pendidikan Bahasa Indonesia, Daerah, Dan Asing, 1(1), 67. doi:10.31540/silamparibisa.v1i1.15

Djajasudarma, F. (2010). Wacana Pemahaman dan Hubungan Antarunsur. Bandung: PT Refika Aditama.

Ibrahim, A. S. (1993). Kajian Tindak Tutur. Surabaya: Usaha Nasional.

Noermanzah, N. (2019). Bahasa sebagai Alat Komunikasi, Citra Pikiran, dan Kepribadian. Seminar Nasional Pendidikan Bahasa dan Sastra, Prosiding Seminar Nasional Bulan Bahasa (Semiba) 2019, https://ejournal.unib.ac.id/index.php/semiba/article/view/11151

Pareke, J., \& Arisandi, F. (2020). Pengakuan Masyarakat Hukum Adat dan Perlindungan Wilayah Adat di Kabupaten Rejang Lebong. Bina Hukum Lingkungan, 4(2), 313. doi:10.24970/bhl.v4i2.135

Prayitno, Harun, Joko. (2010). Teknik dan Strategi Tindak Kesantunan Direktif di Kalangan Andik SD Berlatar Belakang Budaya Jawa. Kajian Linguistik dan Sastra, 23(2), 205-206,UMS.

Rahardi, R. K. (2008). Pragmatik Kesantunan Imperatif Bahasa Indonesia. Jakarta: Erlangga.

Safira, A. (2020). Tindak Tutur Direktif Pelatih Drum Corps Sabda Kinnara Drum Corps. Alinea: Jurnal Bahasa, Sastra, dan Pengajaran, 9(2), 127. doi:10.35194/alinea.v9i2.956

Setiadi, E. M. dkk. (2006). Ilmu Sosial dan Budaya Dasar. Jakarta: Kencana.

Siddik, A. (1980). Hukum Adat Rejang. Jakarta: Balai Pustaka Badan Pusat Statistik Kabupaten Lebong. 
Suartina, T. (2020). Marginalisasi Hukum Adat pada Masyarakat Adat The Marginalization of Adat Law on Adat Communities. Jurnal Masyarakat dan Budaya, 22(1), 27-28. doi:10.14203/jmb.v22i1.936

Sudaryanto. (1990). Menguak Fungsi Hakiki Bahasa. Yogyakarta: Duta Wacana.

Syafryadin, Wardhana, D.E.C, \& Noermanzah. (2020). Maxim Variation, Conventional, and Particularized Implicature on Students' Conversation. International Journal of Scientific and Technology Research, 9(2).

Tim Pemetaan Bahasa. (2008). Bahasa dan Peta Bahasa di Indonesia. Jakarta: Pusat Bahasa, Departemen Pendidikan Nasional.

Yani, I. (2016). Nilai-Nilai Agama dalam Pernikahan Adat Suku Rejang Kecamatan Amen Kabupaten Lebong. Diploma Thesis, IAIN Bengkulu. http://repository.iainbengkulu.ac.id/429/ 